\title{
Refletindo sobre o ensino de ciências com professores dos anos iniciais por meio de uma sequência de ensino investigativo
}

Cristiane Santi Chaves Rodrigues cris.santi@gmail.com

orcid.org/0000-0003-2448-8939 Universidade Estadual de Maringá, Maringá, Paraná, Brasil

Maria Aparecida Rodrigues aparecidar@gmail.com Universidade Estadual de Maringá, Maringá, Paraná, Brasil

\begin{abstract}
RESUMO
Diversas pesquisas têm evidenciado a importância de se inserir o ensino de ciências (EC) desde os primeiros anos de escolarização. Neste contexto, estudos também apontam que a aprendizagem de temas científicos se torna mais eficaz quando a abordagem se dá de forma investigativa. Neste artigo, discutimos parte dos resultados de uma pesquisa de mestrado. O estudo tem como objetivo investigar a contribuição de um curso de extensão sobre ensino de ciências por investigação para professores dos anos iniciais. Para a presente pesquisa, adotamos uma abordagem qualitativa, utilizando como instrumento de coleta de dados uma Sequência de Ensino Investigativo (SEI) com o tema órgãos dos sentidos. Participaram do curso, promovido pela Universidade Estadual de Maringá, seis professores, os quais desenvolveram uma série de atividades, como respostas a questionários e discussões sobre ensino por investigação por meio de textos e atividades práticas. Várias dessas atividades práticas faziam parte da SEI, que possibilitou intensas discussões com os professores participantes. Como atividade final do curso, os professores, em duplas ou individualmente, elaboraram uma sequência de aulas sobre um tema de ciências de sua escolha, procurando contemplar o ensino por investigação (EI). Os dados registrados por meio de gravação em áudio foram analisados de acordo com os pressupostos da análise de conteúdo de Bardin. Os resultados revelaram que as atividades desenvolvidas no contexto do curso de extensão propiciaram a reflexão dos professores sobre a própria prática pedagógica e a inserção do El no desenvolvimento de temas de ciências nos anos iniciais.
\end{abstract}

PALAVRAS-CHAVE: Ensino por investigação. Ensino de ciências. Formação docente. 


\section{INTRODUÇÃO}

Em meio aos avanços científicos e tecnológicos alcançados no século XIX, o reconhecimento da importância da ciência foi intensificado na sociedade, provocando mudanças no pensamento e nas ações sociais. Dessa forma, o EC, que antes não tinha espaço próprio nas escolas, passou a ser tratado como disciplina específica. Segundo Krasilchik (1988, p.56), tal mudança desencadeou a "necessidade de se construir nações democráticas com cidadãos conscientes de seus direitos e deveres, capazes de opinar a respeito dos destinos da ciência e da tecnologia".

A partir do século XX, o EC passou a ter como preocupação a formação cidadã. A autora ainda destaca que as disciplinas científicas passaram a ter "a função de desenvolver o espírito crítico com o exercício do método científico. $O$ cidadão seria preparado para pensar lógica e criticamente e assim tornar-se-ia capaz de tomar decisões com base em informações e dados" (KRASILCHIC, 2000, p.86).

A inserção do EC nas primeiras etapas da vida escolar vem sendo cada vez mais discutida entre estudiosos que a defendem como forma de contribuir não só para a construção de conhecimentos científicos, mas também para a ampliação da produção de significados e para o exercício da função de cidadão crítico (LORENZETTI; DELIZOICOV, 2001; LIMA; MAUÉS, 2006; ZANON; FREITAS, 2007; SASSERON; CARVALHO, 2008; 2013).

De acordo com esses pesquisadores, o desenvolvimento de conhecimentos científicos, a partir dos primeiros anos de escolarização, se faz necessário, desde que sejam respeitadas as habilidades e o desenvolvimento cognitivo da criança. É pertinente destacar, também, que o EC pode auxiliar, de forma significativa, no processo de desenvolvimento da leitura e da escrita da criança. Por meio da comunicação com diferentes tipos de linguagens e fazendo uso de instrumentos de cunho científico que podem ser incorporados nas abordagens de temas científicos em sala de aula, propiciaremos condições para que o educando produza significados, ampliando sua cultura e seu entendimento de mundo (LORENZETTI; DELIZOICOV, 2001). Para Lima e Maués (2006), o EC se constitui como um espaço rico de vivências, com metas definidas, partindo da compreensão de mundo da criança, de suas necessidades e possibilidades.

Levando em conta a importância de se inserir o EC já nos anos iniciais, o presente trabalho integra uma pesquisa de mestrado, que versa sobre as reflexões de professores dos anos iniciais do ensino fundamental acerca do EC por investigação.

Nesse contexto, a questão norteadora foi: Qual sentido os professores dos anos iniciais atribuem ao ensino por investigação ao desenvolverem uma sequência de ensino investigativo em um curso de extensão?

Para responder a essa interrogação, tivemos como objetivo principal identificar a contribuição de um curso de extensão sobre EC por investigação na produção de significados por professores dos anos iniciais acerca desse tema.

A seguir, apontamos, de forma sucinta, elementos importantes do EC no ensino fundamental, dando ênfase às características e opções para o descrevemos os procedimentos metodológicos da pesquisa e discutimos parte dos 
seus resultados. Por fim, tecemos algumas considerações acerca das questões investigadas.

\title{
ENSINO DE CIÊNCIAS NO ENSINO FUNDAMENTAL
}

As etapas de escolarização, desde a educação infantil até o ensino médio, são de responsabilidades municipal, estadual e federal. Cabe a cada instituição a adequação curricular e de planejamentos para o atendimento dos diversos níveis de ensino, assegurando a formação básica comum, respeitando sempre os valores para uma formação pessoal, intelectual, científica e social (BARRETO, 2000).

Para compreendermos o EC no ensino fundamental, devemos tomar como base as perspectivas constantes nos documentos oficiais que garantem a educação básica: Diretrizes Curriculares Nacionais para o Ensino Fundamental de 9 (nove) anos (BRASIL, 2013) e o Currículo da Educação Infantil e Anos Iniciais do Ensino Fundamental (MARINGÁ, 2012). Importante esclarecer que o ensino fundamental é articulado em duas fases: a primeira (1으 ao 5으 ano), assumida pelo município, e a segunda (6 ao 9ㅇ ano), que é de responsabilidade compartilhada entre estado e municípios.

Segundo Barreto (2000), o currículo é a trajetória que orienta o processo ensino-aprendizagem. Cada município adota diferentes princípios ordenadores para a elaboração dos currículos, pensando a realidade de cada estabelecimento.

\begin{abstract}
Os princípios ordenadores do currículo estão fortemente ancorados em problemáticas da sociedade contemporânea, como a construção da identidade, a análise das relações sociais geradas no e pelo trabalho e a valorização deste, a preservação do meio ambiente e da saúde, o conhecimento e o respeito à diversidade das expressões culturais e a condenação de quaisquer formas de discriminação (BARRETO, 2000, p.28).
\end{abstract}

No contexto da escolarização, o Currículo da Educação Infantil e Anos Iniciais do Ensino Fundamental para o município de Maringá/PR está amparado na pedagogia histórico-crítica, a qual se fundamenta na teoria histórico-cultural (Vygotsky) e no materialismo histórico-dialético. Essa proposta apresenta eixos norteadores que visam "oportunizar a apropriação do conteúdo numa perspectiva de desenvolver o trabalho com noções conceituais (MARINGÁ, 2012, p.207)" e que estão dispostos em conteúdos estruturantes, considerados saberes fundamentais e essenciais para a compreensão dos objetivos de estudo.

De modo a organizar os temas de ciências, o currículo é norteado pelos seguintes conteúdos estruturantes: Sistema Solar, Planeta Terra, Fontes de Energia, Corpo Humano, Seres Vivos e Ambiente. Tais conteúdos são abordados com diferentes aprofundamentos do 1 으 ao 5 o ano do ensino fundamental, ou seja, cada etapa desenvolve um conteúdo com objetivos específicos, atendendo às necessidades e respeitando as habilidades e a compreensão de cada etapa escolar, considerando que o conhecimento científico "[...] se expressa pela necessidade de entendê-lo em movimento e não de forma estática, pronto e acabado" (MARINGÁ, 2012, p.207).

O processo de alfabetização da criança começa mesmo antes do início da frequência escolar, por meio dos estímulos e das interações vivenciadas em seu dia a dia. Pensando nisso, é possível compreender a importância de incluir o EC 
desde as primeiras etapas da escolarização. Diante da preocupação com a alfabetização e o letramento infantil nos anos iniciais do ensino fundamental, pesquisas como a de Nigro e Azevedo (2011) apontam que a importância atribuída à disciplina de ciências, nessas séries, geralmente é prejudicada pelo tempo dedicado ao ensino da leitura e da escrita.

Uma das dificuldades dos professores do ensino fundamental é entender que, ao desenvolverem temas de ciências em suas aulas, também alfabetizarão, tanto nos códigos oral e escrito quanto no desenvolvimento do conhecimento científico. Lorenzetti e Delizoicov (2001) argumentam que o EC pode contribuir significativamente para o desenvolvimento desses aspectos. Tais argumentações também são contempladas nos Parâmetros Curriculares Nacionais (PCN):

Desde o início do processo de escolarização e alfabetização, os temas de natureza científica e técnica, por sua presença variada, podem ser de grande ajuda, por permitirem diferentes formas de expressão. Não se trata somente de ensinar a ler e escrever para que os alunos possam aprender Ciências, mas também de fazer usos das Ciências para que os alunos possam aprender a ler e a escrever (BRASIL, 1997, p.62).

Em meio à importância do desenvolvimento de temas de ciências nos anos iniciais, não podemos deixar de considerar o quanto é fundamental a mediação do professor no processo de ensino-aprendizagem, sendo ele quem estimulará, por meio de questionamentos e intervenções, as crianças a interagirem, argumentarem e proporem soluções, proporcionando condições para elas compreenderem seus saberes cotidianos, aproximando-os dos conhecimentos científicos (CARVALHO et al, 1998).

Essa maneira de desenvolver conhecimentos de ciências com os educandos é denominada por vários pesquisadores como $\mathrm{El}$, o qual pode ser também uma forma de alfabetizar cientificamente, pois oportuniza a participação do estudante em seu processo evolutivo de construção do conhecimento. A seguir, apresentamos uma revisão sobre essa abordagem de ensino.

\section{ENSINO DE CIÊNCIAS POR INVESTIGAÇÃO}

O ensino de ciências por investigação tem se respaldado na teoria de John Dewey (1959) e vem sendo lapidado por diversos autores, dentre os quais destacamos: AZEVEDO, 2004, 2008; CAMPOS; NIGRO, 1999; LIMA; MAUÉS, 2006; ZÔMPERO; LABURÚ, 2011, 2012; SASSERON; CARVALHO, 2008, 2013. Com um El, pretendemos promover imagens diferenciadas do EC, deixando de lado o ensino baseado na memorização, com propostas de atividades que permitirão, ao educando, desenvolver autonomia, tornando-se o construtor do próprio conhecimento. Por isso, para a maioria desses autores, o El, além de se destacar como uma das formas de rompermos com uma educação centrada na aprendizagem mecânica, na qual o aluno apenas decora o conteúdo, sem construir um significado do conceito, propicia também outras potencialidades, como o desenvolvimento do pensamento crítico e a capacidade de argumentação.

Assim, o El pode ser uma abordagem eficaz na construção do conhecimento científico da criança, pelo fato de partir de uma situação-problema, que leva em consideração os conhecimentos prévios do educando, a tomada de atitude para 
propor hipóteses, promover a argumentação e a interação social, podendo ser uma boa alternativa para elevarmos a qualidade do processo de ensinoaprendizagem (CARMO; CARVALHO, 2012).

Há que se ressaltar que o El abrange diversas etapas. Parte da proposição de um problema, uma situação especialmente elaborada que possa aguçar a curiosidade dos alunos, estimulando o raciocínio, para levantar hipóteses, no sentido de solucionar a questão. Após a devida problematização, deve ser realizada a inserção de conceitos científicos que auxiliarão na mudança dos conhecimentos prévios e na produção de novos conhecimentos. Em seguida, é realizada a sistematização mediada pelo professor, etapa na qual os educandos reforçarão a construção do conhecimento científico e, para finalizar, a avaliação é desenvolvida de maneira formativa.

Esclarecemos que uma situação-problema se trata de uma situação bem elaborada que possa instigar os alunos, fazendo-os pensar e propor soluções para a mesma. A problematização do conteúdo científico, desde que devidamente contextualizada, pode contribuir para a reflexão da vida cotidiana, para o pensamento crítico, é capaz de auxiliar na resolução de problemas sociais e na construção de conhecimentos universais de forma muito mais consistente do que a aprendizagem por transmissão ou recepção (AULER; DELIZOICOV, 2001).

De acordo com Azevedo (2004), o problema deve ser apresentado para o aluno, preferencialmente em forma de pergunta que estimule a curiosidade dele e o levantamento de hipóteses, manifestadas por meio de discussões, coleta ou análise de dados. Existem outras possibilidades para problematizarmos conhecimentos científicos com os alunos, tais como a narração ou leitura de uma história, uma observação a ser realizada, uma atividade experimental, entre outras. Dessa forma, entendemos que o El, como estratégia de ensinoaprendizagem, pode promover a motivação dos estudantes em um processo de construção de conhecimento, seja ele cotidiano ou científico.

Ressaltamos, portanto, as potencialidades do El, buscando um diálogo com os autores que discorrem sobre essa questão. Segundo Azevedo (2008, p.31), "a investigação consiste, exatamente, na busca incessante pela solução de um problema proposto". Zômpero e Laburú (2012, p.676), por sua vez, argumentam que "essa abordagem propõe-se um ensino em que o aluno tenha um papel intelectual bastante ativo na construção de seu conhecimento. O foco dessa abordagem não fica restrito apenas à aprendizagem dos conteúdos disciplinares".

Integrando essas características, Lima e Maués (2006) explicitam que o EI possibilita que os estudantes interajam com o mundo natural, explorando-o e experimentando-o. Os estudantes não ficam restritos à manipulação mecânica de objetos, atividades puramente lúdicas ou apenas de comprovação de leis e teorias. Assim, compreendemos que o El comporta um enredo construtivista, concordando com Carvalho et al (1998), ao enfatizarem a importância da autonomia do aluno, considerando que a atitude tanto do professor quanto a do aluno, no ambiente de aprendizagem, é que fará com que sejam aumentadas as habilidades da criança em compreender os temas ensinados e os processos de raciocínio envolvidos. Ainda, de acordo com os mesmos autores, a mediação realizada pelo professor, por meio de estímulos que desenvolvam nos alunos a autonomia e a interação social, ajudará a aprimorar o desenvolvimento das habilidades de raciocínio da 
criança e do processo de compreensão dos temas científicos trabalhados em sala de aula.

Nessa perspectiva, reconhecemos que as atividades, no contexto da aprendizagem, para que sejam consideradas investigativas, devem conduzir os alunos a observar, refletir, propor, explicar, elaborar hipóteses, analisar os dados fornecidos, assim como estimular a curiosidade científica (CARVALHO, 2013; ZÔMPERO; LABURÚ, 2011). Complementando a discussão, apoiamo-nos em Sasseron e Carvalho (2011), as quais também ressaltam que o El ocorre em um processo cíclico e que, ao final de cada ciclo, é importante que seja planejada uma avaliação com caráter formativo. Para sistematizar o que foi ensinado, é imprescindível que façamos um resgate dos conhecimentos prévios, oportunizando a produção de significados e a mudança de atitude do educando, permitindo a construção do próprio conhecimento, em um processo de ensinoaprendizagem mais significativo.

Em se tratando da utilização da abordagem investigativa nas aulas de ciências dos anos iniciais do ensino fundamental (foco deste trabalho), Letta (2014) ressalta que é primordial o registro das ideias para solucionar os problemas apresentados. Esses registros contribuirão para a construção do conhecimento científico, de forma a produzir a modificação do conhecimento prévio do aluno. A autora destaca, ainda, que, em uma atividade de cunho investigativo, o aluno precisa se envolver na situação proposta, participando ativamente das discussões, compartilhando seus entendimentos. Entendemos que isso somente será possível se o professor contribuir durante o processo, desenvolvendo seu papel. Ou seja, o professor precisa atuar como mediador, orientando e assessorando o desenvolvimento das atividades, motivando as falas e ações dos alunos, praticando, assim, o ensino de forma investigativa.

\section{PERCURSO METODOLÓGICO}

Nesta pesquisa, adotamos uma metodologia de caráter qualitativo, defendida por Minayo (2012) como aquela que concede, ao pesquisador, uma análise do seu ambiente, de forma interpretativa, dando sentido aos fenômenos ali presentes:

\footnotetext{
A pesquisa qualitativa [...] trabalha com o universo dos significados, dos motivos, das aspirações, das crenças, dos valores e das atitudes. Esse conjunto de fenômenos humanos é entendido aqui como parte da realidade social, pois o ser humano se distingue não só por agir, mas por pensar sobre o que faz e por interpretar suas ações dentro e a partir da realidade vivida e partilhada com seus semelhantes (MINAYO, 2012, p.21).
}

Ainda, de acordo com a autora, a pesquisa qualitativa é estruturada em três etapas, denominadas Ciclo de Pesquisa e constituídas pela "fase exploratória; trabalho de campo e pela análise e tratamento do material empírico e documental" (MINAYO, 2012, p.26).

A pesquisa foi desenvolvida no contexto de um curso de extensão do qual participaram seis professores pedagogos (dois graduandos e quatro graduados), atuantes nos anos iniciais do ensino fundamental. O curso, promovido pela Universidade Estadual de Maringá, teve como objetivo oferecer a oportunidade para professores dos anos iniciais conhecerem e refletirem sobre o El no EC. Esse 
curso foi desenvolvido pelas pesquisadoras no mês de setembro de 2016, com duração de 12 horas e se deu em três etapas: uma apresentação teórica acerca do El, o desenvolvimento da SEI sobre o tema órgãos dos sentidos com o intuito de produzir significados entre os professores acerca do El, e a elaboração de sequências de aulas investigativas pelos professores participantes.

Há que ressaltarmos também que, no início do curso, os professores responderam, por escrito, a um questionário diagnóstico com questões abertas acerca do El e de elementos da prática do EC. O objetivo era conhecer o que esses professores já compreendiam a respeito de EC por investigação. Seguem, na íntegra, as questões que foram respondidas pelos professores: 1) O que você entende por EI? 2) Em sua prática docente, você já desenvolveu, com seus alunos, alguma atividade de forma investigativa? Em caso afirmativo, comente um pouco sobre sua experiência. 3) Que tipo de recursos didáticos você mais utiliza em suas aulas? a) leitura de textos; b) vídeos; c) trabalhos em grupos; d) atividades experimentais; e) visitas de campo; f) outros, quais?

No Quadro 1, reunimos as atividades desenvolvidas no curso de extensão.

Quadro 1 - Resumo das atividades desenvolvidas durante o curso de extensão.

\begin{tabular}{|c|c|c|}
\hline Encontros & Pautas & Atividades \\
\hline 1 & $\begin{array}{l}\text { Apresentação (sujeitos da pesquisa/ } \\
\text { pesquisadora); } \\
\text { Aplicação do questionário diagnóstico; } \\
\text { Discussões: prática docente atual, } \\
\text { dificuldades e facilidades encontradas ao } \\
\text { longo da experiência profissional; } \\
\text { Aspectos teóricos e metodológicos do El. }\end{array}$ & $\begin{array}{l}\text { Levantamento de } \\
\text { conhecimentos prévios; } \\
\text { Apresentação de slides: } \\
\text { Introdução ao ensino de } \\
\text { ciências por investigação; } \\
\text { Discussão de texto adaptado } \\
\text { de Zômpero e Laburú. }\end{array}$ \\
\hline II & $\begin{array}{l}\text { Desenvolvimento da Sequência de ensino } \\
\text { investigativo: Órgãos dos Sentidos. }\end{array}$ & $\begin{array}{l}\text { I) Investigação da fruta; } \\
\text { II) Bala sabor de quê? } \\
\text { III) O olfato e o paladar; } \\
\text { IV) O paladar e a visão. }\end{array}$ \\
\hline III & $\begin{array}{c}\text { Reflexão; } \\
\text { Elaboração, apresentação e avaliação; } \\
\text { Síntese. }\end{array}$ & $\begin{array}{c}\text { Contribuições da SEI: } \\
\text { conhecimentos prévios, } \\
\text { questionamentos durante a } \\
\text { aula, abordagens } \\
\text { investigativas; } \\
\text { Elaboração de sequências de } \\
\text { aula com abordagem } \\
\text { investigativa. }\end{array}$ \\
\hline
\end{tabular}

Fonte: Autoria própria (2017).

Os dados coletados tanto por gravação em áudio como por registros escritos foram transcritos na íntegra e analisados com base nos pressupostos da análise de conteúdo de Bardin (2002, p.42). Ainda de acordo com essa autora, a análise de conteúdo consiste em procedimentos, sistemáticos e objetivos de descrição do conteúdo das mensagens, indicadores (quantitativos ou não) que permitam a inferência de conhecimentos relativos às condições de produção/recepção (variáveis inferidas) destas mensagens. 
Podemos dizer, portanto, que é um conjunto de instrumentos por meio dos quais é possível realizarmos a exploração dos documentos e a identificação dos principais conceitos ou objetos em um texto. Esse reconhecimento é visto como uma sequência de elementos isoláveis por meio de regras. Para tanto, Bardin (2002) recomenda algumas especificações que visam à fidedignidade das análises dos dados, como exaustividade - em que devemos esgotar a totalidade da comunicação, não omitindo nada; exclusividade - segundo a qual um elemento não deve ser classificado em mais de uma categoria; representatividade - a amostra deve representar o universo pesquisado; homogeneidade - os dados obtidos devem se referir ao mesmo tema, ou seja, em sua obtenção, as técnicas precisam ser iguais; pertinência - no que concerne aos documentos, estes precisam se adaptar ao conteúdo e ao objetivo da pesquisa.

A análise dos dados deste trabalho se constituiu das seguintes fases: a préanálise, a exploração do material, a categorização, o tratamento dos resultados e a interpretação.

Na primeira fase, ocorreram a sistematização das ideias iniciais, a fase de organização e o período de intuições. Nessa etapa, foi realizada a transcrição dos questionários respondidos pelos professores, dos áudios resultantes do curso de extensão e dos materiais elaborados pelos professores como atividade final do curso, constituindo, assim, o corpus da pesquisa. Após a transcrição, realizamos a leitura flutuante, por meio da qual escolhemos os indicadores que fundamentariam a interpretação adiante.

A fase de exploração do material versa, essencialmente, sobre operações de codificação, decomposição ou enumeração dos dados, que se deu após inúmeras leituras e releituras do corpus. Ocorreu, assim, a apropriação do texto, possibilitando a retirada de ideias, as quais reuniram um grupo de elementos, definidos como unidades de análise, advindas dos trabalhos por meio do recorte do sentido e não da forma, podendo ser frases ou parágrafos, os quais denominamos fragmentos, que consideramos essenciais para o trabalho (BARDIN, 2002).

Por fim, a última fase do processo de análise é o tratamento dos resultados, que se constitui na categorização que "[...] tem como primeiro objetivo [...] fornecer, por condensação, uma representação simplificada dos dados brutos" (BARDIN, 2002, p.145-149).

Para a análise dos dados, tomamos como referência as respostas dos questionários, bem como as discussões que ocorreram durante o desenvolvimento da SEI, as quais foram transcritas na íntegra. Das respostas dos professores ao questionário, emergiram três categorias, a saber: compreensão sobre ensino investigativo, atividades investigativas e modalidades didáticas. E das falas transcritas referentes à discussão da SEI, identificamos as seguintes categorias: importância do ensino de ciências nos anos iniciais, dificuldades para desenvolver temas de ciências e reflexão sobre a prática.

Para validar os resultados obtidos, ressaltamos que os professores foram identificados por códigos. Por exemplo, P1 = Professor 1.

É importante ressaltar que, neste trabalho, daremos maior ênfase aos resultados obtidos por meio do desenvolvimento dos aspectos teóricos e metodológicos do EC por investigação, bem como do desenvolvimento da SEI 
sobre órgãos do sentido com os participantes do curso de extensão. Estes resultados foram importantes para avaliarmos a reflexão dos professores acerca dessa abordagem de ensino.

Esclarecemos que os resultados obtidos por meio da elaboração de materiais didáticos pelos professores, por questão de espaço, farão parte de outro trabalho.

\section{RESULTADOS E DISCUSSÕES}

A partir das respostas ao questionário diagnóstico, obtidas no início do curso de extensão, foi possível observar o que os professores compreendem sobre o El. Constatamos que alguns deles já desenvolveram atividades com características investigativas e que todos eles empregam diversas modalidades didáticas no desenvolvimento de suas práticas pedagógicas. Portanto, do conteúdo das respostas referentes ao questionário, emergiram três categorias:

1 - Compreensão sobre ensino investigativo;

2-Atividades investigativas;

3 - Modalidades didáticas.

A categoria 1 (compreensão sobre ensino investigativo) se desmembrou em quatro subcategorias, conforme mostra o Quadro 2, apresentado a seguir:

Quadro 2 - Categorias, subcategorias e unidades de análise referentes à compreensão dos professores em relação ao ensino por investigação.

\begin{tabular}{|c|c|c|}
\hline Categorias & Subcategorias & $\begin{array}{c}\text { Unidades de } \\
\text { Análise }\end{array}$ \\
\hline \multirow{4}{*}{\begin{tabular}{c} 
1 $\begin{array}{c}\text { 1.1 Metodologia de ensino } \\
\text { ensino investigativo }\end{array}$ \\
\cline { 2 - 3 }
\end{tabular}} & $\begin{array}{c}\text { P1, P2, P4, } \\
\text { P5 }\end{array}$ \\
\cline { 2 - 3 } & $\begin{array}{c}1.2 \text { Construção de conhecimento pelo } \\
\text { educando }\end{array}$ & P5, P6 \\
\cline { 2 - 3 } & $\begin{array}{c}1.3 \text { Autonomia do educando na busca } \\
\text { do conhecimento }\end{array}$ & P6 \\
\cline { 2 - 3 } & 1.4 Visão equivocada & P3 \\
\hline
\end{tabular}

Fonte: Autoria própria (2017).

Podemos observar que, dos seis participantes, quatro concebem o El como metodologia de ensino, como exemplificam dois dos fragmentos de respostas:

P1: "Entendo o El como uma metodologia de o aluno aprender por meio da pesquisa em diferentes recursos e materiais".

P4: "El deve ser uma metodologia que parte de um problema, um conteúdo de interesse dos alunos ou da turma, para pesquisar, aprofundar [...]"

Os entendimentos apresentados por esses professores se aproximam das ideias de vários autores, dentre os quais destacamos Miranda, Suart e Marcondes (2015), que tratam o El como uma metodologia de ensino.

Destacamos que a professora P5, além de se referir ao El como metodologia de ensino, argumentou também que, por meio dele, pode-se buscar a construção do conhecimento. Já a professora P6, embora não tenha mencionado esse ensino 
como metodologia, considera importante a busca de conhecimento pelo educando. É o que indicam os fragmentos de suas respostas:

P5: "[...] que busque a construção do conhecimento junto ao educando e não simplesmente a transmissão do conhecimento pelo professor".

P6: "A busca do conhecimento, pelo educando acompanhado pelo professor $[\ldots]^{\prime \prime}$.

A questão da construção do conhecimento apontada por essas professoras vai ao encontro da linha de pensamento de Carvalho (2013 p.2), quando enfatiza que essa abordagem "proporciona condições para que o aluno possa raciocinar e construir o conhecimento".

Com a categoria 2 (atividades investigativas desenvolvidas), buscamos identificar se os professores já haviam desenvolvido alguma atividade investigativa. As seis subcategorias que emergiram de suas respostas estão organizadas no Quadro 3, com suas respectivas unidades de análise.

Quadro 3 - Categorias, subcategorias e unidades de análise referentes às atividades investigativas desenvolvidas pelos participantes.

\begin{tabular}{|c|c|c|}
\hline Categorias & Subcategorias & $\begin{array}{c}\text { Unidades de } \\
\text { Análise }\end{array}$ \\
\hline \multirow{6}{*}{$\begin{array}{l}2 \text { - Atividades investigativas } \\
\text { desenvolvidas }\end{array}$} & $\begin{array}{c}2.1 \text { Importância do Sol e da água no } \\
\text { desenvolvimento de plantas }\end{array}$ & P3 \\
\hline & 2.2 Importância do ar para as plantas & P4 \\
\hline & $\begin{array}{l}2.3 \text { Não considera ter desenvolvido } \\
\text { atividades investigativas e, sim, para } \\
\text { comprovação da teoria }\end{array}$ & P5 \\
\hline & 2.4 Não sabe dizer se já realizou & $\mathrm{P} 2$ \\
\hline & 2.5 Não realizou & P1 \\
\hline & 2.6 Não respondeu & P6 \\
\hline
\end{tabular}

Fonte: Autoria própria (2017).

Observamos que, dos seis professores, dois (P3 e P4) desenvolveram atividades de cunho investigativo e relatam envolver os alunos em momentos de observação e registros, especialmente $\mathrm{P} 3$, que orientou seus alunos a desenharem, semanalmente, o que vinha acontecendo com as plantas em observação. Os fragmentos a seguir demonstram a experiência desses professores.

P3: "[...] em um espaço da escola os alunos plantaram salsinha, manjericão, hortelã e cebolinha, durante o processo foi ressaltado a importância do sol e da água para o desenvolvimento dos seres vivos, os alunos ilustraram semanalmente o desenvolvimento das plantas, e eles demonstraram bastante entusiasmo, preocupação em regar, inclusive alguns jogavam água sempre que saíam da sala (rsrs) escondido".

P4: "Na minha prática docente uma atividade investigativa que realizei foi pesquisa sobre a importância do ar, com leitura de textos informativos, literaturas, experiência com uma planta na qual colocamos um saquinho e pode-se observar que as plantas respiram". 
É possível notar, na resposta fornecida por P3, elementos de um ensino com caráter investigativo. De acordo com Campos e Nigro (1999), é fundamental que as observações sejam documentadas. Quanto à categoria 3 (modalidades didáticas), foi possível observar que os professores empregam uma diversidade delas em suas práticas. O Quadro 4 reúne as diferentes modalidades apontadas pelos professores, bem como as unidades de análise que as compõem.

Quadro 4 - Categorias, subcategorias e unidades de análise em relação às modalidades didáticas utilizadas pelos professores.

\begin{tabular}{|c|c|c|}
\hline Categorias & Subcategorias & $\begin{array}{l}\text { Unidades de } \\
\text { Análise }\end{array}$ \\
\hline \multirow{9}{*}{3 - Modalidades didáticas } & 3.1 Leitura de textos & $\begin{array}{l}\text { P1, P2, P3, } \\
\text { P4, P5, P6 }\end{array}$ \\
\hline & 3.2 Trabalhos em grupos & P1, P2, P6 \\
\hline & 3.3 Atividades experimentais & P2, P4, P5 \\
\hline & 3.4 Vídeos & P2, P3, P5 \\
\hline & 3.5 Pesquisas com a família & P4 \\
\hline & 3.6 Visitas de campo & P5 \\
\hline & $\begin{array}{c}\text { 3.7 Elaboração própria de material } \\
\text { didático }\end{array}$ & P1, P6 \\
\hline & $\begin{array}{l}\text { 3.8 Brincadeiras lúdicas com material } \\
\text { concreto }\end{array}$ & P2 \\
\hline & 3.9 Música & P1 \\
\hline
\end{tabular}

Fonte: Autoria própria (2017).

Esclarecemos que os professores, além de assinalarem todas as alternativas relacionadas no enunciado da questão, trouxeram outras estratégias de ensino que utilizam em suas aulas, como, por exemplo, pesquisas com a família, brincadeiras lúdicas com material concreto e música. Todos afirmaram empregar a leitura de textos, demonstrando preocupação com a aprendizagem dos códigos oral e escrito.

No primeiro momento do curso, antes de iniciar a abordagem acerca do El, buscamos, por meio de uma conversa mediada pela primeira pesquisadora, questionar os professores sobre o que pensam a respeito do EC nos anos iniciais e também como realizam o trabalho com seus alunos no dia a dia, em sala de aula. Após as discussões, que revelaram elementos importantes acerca da prática dos professores participantes da pesquisa, demos início ao desenvolvimento dos aspectos teóricos acerca do El.

Com a apresentação e a discussão acerca do El, exploramos sua definição, suas características, bem como os autores que o defendem e o recomendam como abordagem para o ensino de conteúdos científicos já nos anos iniciais, tendo em vista sua relevância na promoção da alfabetização científica. É importante ressaltar que, no contexto das discussões promovidas, a primeira pesquisadora destacou a relevância de se trabalhar temas de ciências, de forma investigativa, no processo de desenvolvimento da leitura e da escrita. Durante o desenvolvimento sobre El, demos oportunidade para os participantes se pronunciarem a respeito dessa tendência de ensino, entre outros aspectos. 
Dentre as primeiras atividades que possibilitaram aos professores manifestar suas ideias, destacamos a leitura e a discussão de um texto adaptado por uma das pesquisadoras, com base no artigo "Implementação de atividades investigativas na disciplina de Ciências em escola pública: uma experiência didática", de Zômpero e Laburú (2012).

O texto em pauta aborda uma atividade investigativa sobre fotossíntese e respiração, realizada em uma escola pública situada na periferia de um município do Estado do Paraná. A atividade foi desenvolvida com 32 alunos do 6o ano, os quais nunca havia tido contato com uma metodologia diferente da tradicional, por isso apresentaram certa resistência à metodologia proposta. $\mathrm{Na}$ atividade em discussão, os autores, após uma introdução sobre os seres vivos, apresentaram um terrário pronto e explicaram também como este poderia ser construído, propondo, em seguida, a questão problema: "A planta conseguirá sobreviver no terrário? De que condições as plantas precisam para sobreviver?".

A partir das discussões promovidas com os professores participantes de nossa pesquisa, foi possível estabelecer três categorias de análise, relacionadas na sequência:

4 - Importância do ensino de ciências nos anos iniciais;

5 - Dificuldades para desenvolver temas de ciências;

6 - Reflexões sobre a prática docente.

Essas três categorias, com suas respectivas subcategorias e unidades de análise, estão reunidas no Quadro 5.

Quadro 5 - Categorias, subcategorias e unidades de análise obtidas das falas dos professores em relação ao desenvolvimento do EC nos anos iniciais.

\begin{tabular}{|c|c|c|}
\hline Categorias & Subcategorias & $\begin{array}{c}\text { Unidades de } \\
\text { Análise }\end{array}$ \\
\hline \multirow{2}{*}{$\begin{array}{l}4 \text { - Importância do ensino } \\
\text { de ciências nos anos iniciais }\end{array}$} & $\begin{array}{l}4.1 \text { Aproximação da linguagem } \\
\text { científica com a linguagem cotidiana }\end{array}$ & P1, P3, P5 \\
\hline & 4.2 Motivação do interesse do aluno & P1, P5 \\
\hline \multirow{5}{*}{$\begin{array}{c}\text { 5- Dificuldades para } \\
\text { desenvolver temas de } \\
\text { ciências }\end{array}$} & 5.1 Formação inicial insuficiente & P1, P5 \\
\hline & $\begin{array}{l}5.2 \text { Inexistência de formação } \\
\text { continuada na área de ciências }\end{array}$ & P2, P3, P5 \\
\hline & 5.3 Prioridade na alfabetização & P2, P4, P5 \\
\hline & 5.4 Planejamento pronto & P2, P3 \\
\hline & 5.5 Falta de materiais & P5 \\
\hline \multirow{2}{*}{$\begin{array}{l}\text { 6- Reflexão sobre a prática } \\
\text { docente }\end{array}$} & 6.1 Teoria como ponto de partida & P1, P3, P5 \\
\hline & $\begin{array}{l}\text { 6.2 Emprego de atividades para } \\
\text { comprovação da teoria }\end{array}$ & P1, P3, P5 \\
\hline
\end{tabular}

Fonte: Autoria própria (2017).

Com a categoria 4 (importância do ensino de ciências nos anos iniciais), identificamos que metade dos professores participantes (P1, P3 e P5) concorda que o EC desenvolvido desde as primeiras etapas da vida escolar da criança é importante. Assim, ressaltamos que boa parte desses professores acredita que é 
possível realizar o desenvolvimento dos códigos oral e escrito com base em temas de ciências e que é importante fazê-lo. Em seus fragmentos de fala, destacam tal importância, relacionando-a com a aproximação das linguagens científica e cotidiana, além de motivar o interesse do aluno:

P1: "Sim, eu penso que na educação infantil é importante, tá, o EC, principalmente que usando alguns conceitos do cotidiano e o que é próprio deles fica bem atrativo e acaba acontecendo todas as disciplinas ao mesmo tempo. E isso é fundamental para envolver a disciplina de ciências, aí é que a responsabilidade se define $[\ldots . . . "$

P2: "Eu acredito que sim, que seja importante o EC ali nos anos iniciais, eu acho que até na educação infantil mesmo. Porque para criança tá vivenciando e rompendo essa questão do núcleo de senso comum para o científico deve começar, sim, desde cedo".

P5: "Acho que eles tanto aprendem, como é uma das disciplinas que eles mais se interessam justamente por acho que por tratar daquilo que é mais natural, né, próximo deles. [...] principalmente quando chega no 4 o e 50 ano que trabalha toda essa questão do corpo humano que eles gostam muito, os sistemas, aí que eles se interessam mais ainda, eles têm muitas perguntas".

Os professores concordam que uma aproximação dos conteúdos escolares com a vivência cotidiana contribui, de forma mais efetiva, para a aprendizagem do aluno. Outro ponto importante, destacado pelos professores, é o interesse natural das crianças pelos temas de ciências, pois geralmente são curiosas, têm vontade de aprender coisas novas.

Segundo Sasseron e Carvalho (2008), o importante, nas primeiras etapas da vida escolar, é que a criança seja envolvida nos ambientes e processos de aprendizagem, despertando o raciocínio, a autonomia e a tomada de decisão para a solução dos problemas, vivenciando novas experiências.

Em relação à prática docente, emergiram das falas dos professores algumas dificuldades para o desenvolvimento dos temas de ciências (categoria 5). As duas primeiras subcategorias estão relacionadas à formação docente. Para os professores participantes, tanto a formação inicial quanto a continuada deixam a desejar em relação ao EC, como pode ser observado nas falas a seguir:

P1: "A disciplina de metodologias de EC, tô iniciando ela agora nesse semestre é de 34 horas só, super-rápida... [...] E a de alfabetização eu estou fazendo há três semestres já e não me sinto preparado para fazer isso".

P5: “É uma pena, que eu acredito, assim, que os professores, eu me coloco nesse meio, a gente tem pouca formação em ciências para trabalhar com os alunos, então nós trabalhamos de maneira muito superficial".

É importante destacar que o professor P1 é graduando em pedagogia, e sua fala reflete a preocupação com a diferença de carga horária entre as disciplinas de alfabetização e de metodologia de EC. Esse cenário, na sua formação inicial, pode vir a comprometer, de alguma forma, sua prática docente.

Viecheneski, Lorenzetti e Carletto (2012) argumentam que boa parte dos professores reconhece a importância do EC, mas não o contempla em sala de aula por insegurança. Nesse contexto, Soares, Mauer e Kortmann (2013) sugerem: 
O professor, mesmo com as dificuldades da prática, necessita buscar constantemente a melhoria de sua formação [...]. A transformação da prática docente se dá quando no momento em que o professor consegue ter a autocrítica de seu fazer em sala de aula e também da sua vida profissional (SOARES; MAUER; KORTMANN, 2013, p.53).

Além das dificuldades relacionadas à formação inicial, os professores argumentaram que não há formação continuada específica na área de ciências. Em geral, as formações continuadas para os professores desse nível de ensino são voltadas para a alfabetização na língua portuguesa e matemática.

P5: "[...] formação dos professores nessa área. Porque principalmente no ensino fundamental I eles se preocupam muito com a formação do professor na área de língua portuguesa e matemática... [...] Não que a universidade dê tanta formação em língua portuguesa e matemática, também fica bastante a desejar, só que, principalmente na escola pública, é, tem, nós temos lá uma quantidade de horas que o município é, o município, o Estado é obrigado a dar a formação continuada".

P3: “[...] no ensino fundamental, eu concordo com a fala da professora P5, que a alfabetização da língua portuguesa e da matemática acaba que... [...] demanda mais tempo [...]"

P2: “Tem mais formação em português e matemática”.

Percebemos a relevância da manifestação dos professores ao afirmarem que a formação continuada é mais frequente em alfabetização. Corroborando essa revelação na fala dos professores, ao consultarmos o site da Secretaria Municipal de Educação (SEDUC) do município, no qual atuam os professores da pesquisa, certificamos que essa secretaria oferece formação continuada ao longo do ano letivo, por meio de convênios com programas federais como o Pró-letramento e o Pacto Nacional para alfabetização na idade certa.

Também é percebida, na fala dos professores P2, P4 e P5, a prioridade dada à alfabetização e ao letramento nos anos iniciais do ensino fundamental:

P5: "[...] o professor foge um pouco das ciências, e ele fica mais na língua portuguesa, porque ele tem mais segurança do que, porque ele tem mais formação".

P2: "Eu também percebo, às vezes, que trabalho muito bem na parte da alfabetização, mas aí em ciências, essa parte prática mesmo, eu quase não trabalho, é mais português mesmo...".

P4: “[...] a gente muitas vezes prioriza muito a alfabetização e a matemática, só dá o texto...".

P5: “É que na verdade é difícil para o professor entender que, com conteúdo de ciências, ele também alfabetiza. Ele podia usar as mesmas palavras lá do EC para alfabetizar...".

Outras dificuldades elencadas estão relacionadas ao planejamento engessado e à falta de recursos para o desenvolvimento de atividades práticas voltadas ao EC. Os professores P2, P3 e P4 afirmam que o exercício de suas práticas se limita pelo envio dos planejamentos prontos pela prefeitura e pela inflexibilidade imposta por meio da equipe pedagógica em exercício. 
P2: “Sim, é engessado, sabe assim. Você pega tudo pronto. As atividades todas certinhas ali, pra você tá aplicando em sala de aula, pouca coisa que pode mudar em uma atividade ou outra. [...]"

P3: "Daí esse planejamento acaba que não dá conta da realidade. Porque a realidade que eu tenho lá no bairro não é a realidade da escola que tem no centro $[\ldots]^{\prime \prime}$

P4: "Mesmo que às vezes venha a sugestão lá de experiência, a gente muitas vezes prioriza muito a alfabetização e a matemática, só dá o texto...".

A liberdade dada ao professor em propor mudanças ou readequações nos planejamentos é bastante salutar e pode refletir na qualidade de sua prática pedagógica. Ainda em relação ao desenvolvimento dos temas de ciências, a professora P5 destaca a falta de materiais que possam auxiliar nas aulas práticas:

P5: "[...] tem conteúdos que ficam muito na superficialidade, né, eu trabalhava, por exemplo, os Reinos lá no 40 ano, você vai falar do Reino Funghi, fungo até dá pra você mostrar pra criança, né, mas você não tem um microscópio pra ele ver, vai falar de bactéria pra ele muito, quem viu bactéria? Ninguém nunca viu, né? Não tem um microscópio pra você mostrar, então acho que falta muito material, faltam alguns recursos [...]".

No contexto das discussões promovidas e diante das dificuldades levantadas no decorrer do curso, a primeira pesquisadora destacou a relevância de se trabalhar temas de ciências de forma investigativa no processo de desenvolvimento da leitura e da escrita, uma metodologia para auxiliar, de forma positiva, o processo ensino-aprendizagem.

A categoria 6 (Reflexão sobre a prática docente) foi estabelecida durante o desenvolvimento sobre $\mathrm{El}$, em que se deu oportunidade para os participantes se pronunciarem a respeito dessa tendência de ensino, entre outros aspectos. Nesse contexto, foi possível perceber uma reflexão dos professores, à medida que repensavam suas práticas.

A atividade de leitura e discussão do artigo "Implementação de atividades investigativas na disciplina de Ciências em escola pública: uma experiência didática", de Zômpero e Laburú (2012), possibilitou aos professores manifestar suas ideias, como podemos observar a seguir:

P1: "[...] Quando eu cheguei aqui (nessa parte do texto), fiquei imaginando minha prática, eu já ia começar pela explicação, pela pesquisa, teria começado de forma errada...".

P5: "la usar a atividade para comprovação, né...".

P1: "Seria um: como acontece... E tá tudo errado, e a gente faz tudo assim...".

P5: "É que na verdade a gente tá acostumado com isso... [...] a gente só faz pra comprovar. Aí estuda o ar, vamos fazer um cata-vento pra ver, né...".

P3: "Porque aqui, nessa experiência, eles eram cientistas, eles tinham que descobrir, e isso é novo pra eles... [...] Na escola, não, a gente faz para comprovar que isso é assim... Vou provar para você que isso é verdade...".

P5: “[...] até porque a pesquisa bibliográfica foi feita depois, e a gente tá acostumado a dar antes [...]" 
Analisando o diálogo apresentado, podemos perceber que a forma como foi conduzida a atividade pelos autores do artigo provocou conflito em alguns professores. Consideramos esses resultados importantes, pois revelam um pouco da prática dos professores participantes da pesquisa, ou seja, eles estão acostumados a desenvolver a teoria e posteriormente realizar algum experimento ou atividade que venham comprovar o conhecimento discutido, ao contrário do apresentado no texto trabalhado. Os professores questionaram a forma adotada no artigo, conforme a qual primeiro se interrogaram os alunos, coletaram-se observações e somente depois é que foi desenvolvida a teoria, propondo-se pesquisa bibliográfica.

Ramos e Rosa (2008, p.303) atentam para o uso de práticas experimentais nas aulas de ciências, pois estas

[...] podem ser usadas como uma ferramenta importante para estimular não só o aprendizado, mas também a convivência em grupo, propiciando trocas entre os sujeitos, necessariamente mediadas pela Cultura na qual estes indivíduos estão inseridos, que comumente não são alcançadas em uma aula meramente expositiva.

Devemos considerar a prática experimental para auxiliar o professor a estimular o desejo dos alunos em querer participar, em querer investigar a situação e desenvolver o conhecimento científico. Portanto, o experimento não deve ser empregado para justificar ou comprovar dada teoria, mas, sim, como ponto de partida para a construção do conhecimento científico.

\section{ALGUMAS CONSIDERAÇÕES}

Não podemos ignorar o fato de vivermos em um mundo influenciado pela ciência e pela tecnologia. Daí a necessidade de propiciarmos, já no início dos anos escolares, uma educação que permita aos alunos desenvolver autonomia para pensar e agir em situações do seu cotidiano, especialmente aquelas que envolvam conhecimentos de ciências. Por isso, os professores que atuam nos anos iniciais precisam pensar em modalidades didáticas que oportunizem, aos alunos, a construção do conhecimento científico a partir do conhecimento de suas vivências. Nesse sentido, o El, como enfatizado neste trabalho, pode ser caracterizado como uma alternativa propícia para os professores desenvolverem sua ação docente, de forma condizente com as necessidades atuais do EC.

Os resultados obtidos a partir da análise do conteúdo das respostas relacionadas ao questionário nos permitiram identificar que a maioria dos professores compreende o El como uma metodologia de ensino e reconhece a importância de desenvolver temas de ciências nos anos iniciais do ensino fundamental. Porém, os professores justificam que não o fazem na prática devido às seguintes dificuldades: formação inicial insuficiente, falta de formação continuada na área de ciências e a prioridade dada à alfabetização nesse nível de ensino.

A partir da análise dos registros produzidos durante as discussões acerca dos aspectos teóricos e metodológicos do El e do desenvolvimento da SEI, pudemos constatar que os professores, ao refletirem sobre suas práticas, revelaram uma visão indutivista de ciência, tendo em vista que, em suas aulas, partem sempre de 
explicações teóricas e fazem uso de atividades práticas para comprovar a teoria estudada. No entanto, nesse processo de reflexão, os professores se questionaram sobre as formas como vinham exercendo o trabalho docente, mencionando, às vezes, que as estratégias adotadas por eles poderiam não estar corretas. A interação com os professores, promovida por meio das discussões realizadas, fez com que eles se sentissem à vontade para compartilhar suas experiências da prática docente, trocando ideias, com a intenção de evoluírem em relação aos trabalhos que vêm desenvolvendo em sala de aula.

Com base nos resultados obtidos, podemos dizer que os objetivos propostos inicialmente neste trabalho foram parcialmente alcançados. Ou seja, podemos inferir que o curso de extensão trouxe contribuições para a formação dos professores, pois se constituiu como um espaço reflexivo importante, que possibilitou questionamentos sobre a prática docente, bem como a produção de significados, ainda que de forma incipiente, sobre o El.

Entendemos que a reflexão dialogada sobre a ação docente pode fornecer novos caminhos para o professor modificar sua prática em sala de aula. Para nós, o espaço reflexivo, proporcionado com o desenvolvimento deste trabalho, pode ter sido um ponto de partida para uma possível transformação na prática desses professores.

Esses resultados nos fazem refletir sobre a importância de estabelecermos parcerias entre universidade e escola básica. Acreditamos que essa pode ser uma das formas de minimizarmos problemas relacionados à formação docente. 


\title{
Reflecting on early childhood science education by means of an inquiry-based learning sequence
}

\begin{abstract}
Several surveys have demonstrated the importance of inserting Science Education (SE) since the early years of schooling. In this setting, researches also point that the learning of scientific topics becomes more effective when the approach happen trough investigation. In this article, we discuss part of the results from a master's degree research. The survey aims to determine the contribution of an extension course about inquiry-based science learning to early childhood education teachers. To the present research, we took a qualitative approach, using as data collection instrument an inquiry-based learning sequence (IBLS) with the sense organs as the subject. Took part at the extension course, promoted by the Universidade Estadual de Maringá (UEM), six teaches that developed a series of activities such as responding to questionnaires and discussing inquiry-based learning by means of texts and practical activities. Several of these practical activities were part of an inquiry-based learning sequence (IBLS), which made intense discussions with the participating teachers possible. As a final activity of the course, the teachers, in pairs or individually, prepared a sequence of classes about a science theme of their choice, trying to include inquiry-based learning. The audio recordings were analyzed according to Bardin content analysis. The results revealed that the activities developed in the extension course fostered the reflection of the teachers as regards the pedagogical practice itself and the insertion of inquiry-based learning into the development of science themes in early childhood education.
\end{abstract}

KEYWORDS: Inquiry-based learning. Science teaching. Teacher training. 


\section{REFERÊNCIAS}

AULER, D.; DELIZOICOV, D. Alfabetização científico-tecnológica para quê? Ensaio Pesquisa em Educação em Ciências, Belo Horizonte, v. 3, n. 1, p.1-13, jul./dez. 2001. Disponível em: <http://www.scielo.br/pdf/epec/v3n2/1983-2117-epec-302-00122.pdf>. Acesso em: 08 out. 2016.

AZEVEDO, M. C. P. S. Ensino por investigação: problematizando as atividades em sala de aula. In: CARVALHO, A. M. P. (Org.) Ensino de ciências: unindo a pesquisa e a prática. São Paulo: Pioneira Thomson Learning, 2004.

AZEVEDO, M. N. Pesquisa-ação e atividades investigativas na aprendizagem da docência em ciências. 2008. 224f. Dissertação (Mestrado) Faculdade de Educação da Universidade de São Paulo, São Paulo, 2008.

BARDIN, L. Análise de conteúdo. Reimpr. São Paulo: Edições 70, 2002.

BARRETO, E. S. S. Tendências recentes do currículo do ensino fundamental no Brasil. In: BARRETO, E. S. S. (Org.) Os currículos do ensino fundamental para as escolas brasileiras. 2 ed. Campinas: Autores Associados, 2000.

BRASIL. Diretrizes curriculares nacionais para o ensino fundamental. Parecer CNE/CEB no 7/2010, aprovado em 7 de abril de 2010. Disponível em: <http://www.portal.mec.gov.br/docman/junho-2013.../13448-diretrizescuriculares-nacionais-2013.pdf>. Acesso em: 05 mai. 2016.

Secretaria de Educação Fundamental. Parâmetros curriculares nacionais: ciências naturais. Brasília: MEC/SEF, 1997. Disponível em: <http://portal.mec.gov.br/seb/arquivos/pdf/livro01.pdf>. Acesso em: 05 mai. 2016.

CAMPOS, M. C. C.; NIGRO, R. G. Didática das ciências: o ensino-aprendizagem como investigação. São Paulo: FTD, 1999.

CARMO, A. B.; CARVALHO, A. M. P. Múltiplas linguagens e a matemática no processo de argumentação em uma aula de física: análise dos dados de um laboratório aberto. Investigações em Ensino de Ciências. v.17, n.1, 2012, p.209226.

CARVALHO. A. M. P et al. Ciências no ensino fundamental: o conhecimento físico. São Paulo: Scipione, 1998. 
- (Org.) Ensino de ciências por investigação: condições para implementação em sala de aula. São Paulo: Cengage Learning, 2013.

DEWEY, J. Democracia e educação. 5 ed. São Paulo: Companhia Editora Nacional, 1959.

KRASILCHIC, M. Ensino de Ciências e a Formação do Cidadão. Em aberto. ano 7, n. 40, 1988, p.55-60.

. Reformas e realidade: o caso do ensino de ciências. São Paulo em

Perspectiva, v. 14, n. 1, 2000, p.85-93.

LETTA, L. A. As ações do professor no ensino fundamental I ao aplicar uma sequência de ensino investigativa (SEI). 2014, 164f. Dissertação (Mestrado) Faculdade de Educação da Universidade de São Paulo, São Paulo, 2014.

LIMA, M. E. C. C.; MAUÉS, E. Uma releitura do papel da professora das séries iniciais no desenvolvimento e aprendizagem de ciências das crianças. Ensaio - Pesquisa em Educação em Ciências. v.8, n.2, 2006, p.161-175.

LORENZETTI, L; DELIZOICOV, D. Alfabetização científica no contexto das séries iniciais. Ensaio - Pesquisa em Educação em Ciências. v.3, n.1, 2001, p.1-17.

MARINGÁ, Currículo da educação infantil e Anos iniciais do ensino fundamental. Prefeitura Municipal de Maringá, Secretaria Municipal de Educação (SEDUC), 2012.

MINAYO, M. C. S.; DESLANDES, S. F.; GOMES, R. Pesquisa social: teoria, método e criatividade. 32. ed. Petrópolis: Vozes, 2012.

MIRANDA, M. S.; SUART, R. C.; MARCONDES, M. E. R. Promovendo a alfabetização científica por meio de ensino investigativo no ensino médio de química: contribuições para a formação inicial docente. Ensaio - Pesquisa em Educação em Ciências. v. 17, n. 3, 2015, p.555-583.

NIGRO, R. G.; AZEVEDO, M. N. Ensino de ciências no fundamental 1: Perfil de um grupo de professores em formação continuada num contexto de alfabetização científica. Ciência e Educação. v. 17, n. 3, 2011, p.705-720. 
iniciais do ensino fundamental. Investigações em Ensino de Ciências. v.13, n.3, 2008, p.299-331.

SASSERON, L. H.; CARVALHO, A. M. P. Almejando a alfabetização científica no ensino fundamental: a proposição e a procura de indicadores do processo. Investigações em Ensino de Ciências. v.13, 2008, p.333-352.

; CARVALHO, A. M. P. Alfabetização científica: uma revisão bibliográfica. Investigações em Ensino de Ciências. v. 16, 2011, p.59-77.

- Interações discursivas e investigação em sala de aula: o papel do professor. In: CARVALHO, A.M.P. (Org.) Ensino de ciências por investigação: condições para a implementação em sala de aula. São Paulo: Cengage Learning, 2013. p.41-62.

SOARES, A. C.; MAUER, M. B.; KORTMANN, G. L. Ensino de ciências nos anos iniciais do ensino fundamental: possibilidades e desafios em Canoas-RS. Revista Educação, Ciência e Cultura. v. 18, n. 1, 2013.

VIECHENESKI, J. P.; LORENZETTI, L.; CARLETTO, M. R. Desafios e práticas para o ensino de ciências e alfabetização científica nos anos iniciais do ensino fundamental. Atos de Pesquisa em Educação. v. 7, n. 3, 2012, p.853-876.

ZANON, D. A. V.; FREITAS, D. A aula de ciências nas séries iniciais do ensino fundamental: ações que favorecem a sua aprendizagem. Ciências \& Cognição. v. 10, 2007, p.93-103.

ZÔMPERO, A. F.; LABURÚ, C. E. Atividades investigativas no ensino de ciências: aspectos históricos e diferentes abordagens. Ensaio - Pesquisa em Educação em Ciências. v. 13, n. 3, 2011, p.67-80.

. Implementação de atividades investigativas na disciplina de ciências em escola pública: uma experiência didática. Investigações em Ensino de Ciências. v. 17, n. 3, 2012, p.675-684. 
Recebido:28 out. 2017

Aprovado:30 jun. 2018

DOI:10.3895/actio.v3n2.7225

Como citar:

RODRIGUES, C. S. C.; RODRIGUES, M. A. Refletindo sobre o ensino de ciências com professores dos anos iniciais por meio de uma sequência de ensino investigativo. ACTIO, Curitiba, v. 3, n. 2, p. 58-79, mai./ago.

2018. Disponível em: <https://periodicos.utfpr.edu.br/actio>. Acesso em: XXX

Correspondência:

Cristiane Santi Chaves Rodrigues

Avenida São Paulo Apóstolo, 265 - Parque Residencial Bom Pastor, Sarandi, Paraná, Brasil.

Direito autoral: Este artigo está licenciado sob os termos da Licença CreativeCommons-Atribuição 4.0

Internacional.

(c) (1) 